\title{
DA PRÁTICA À TEORIA - O CONTO NA PERSPECTIVA DE QUATRO CONTISTAS
}

\section{FROM PRACTICE TO THEORY - THE STORY FROM THE PERSPECTIVE OF FOUR SHORT-STORY WRITERS}

\author{
Rosa Maria Severino Ueno ${ }^{1}$
}

DOI: 10.26512/aguaviva.v3i1.12205

Recebido em: 02 abr. 2018

Aceito em: 04 mai. 2018

RESUMO: Neste artigo, discorreremos sobre o conto como um gênero literário autônomo. Para tanto, revisitaremos alguns textos de pretensões teóricas de destacados contistas dos séculos XIX e XX, a saber: Edgar Alan Poe, Anton Tchekhov, Horacio Quiroga e Julio Cortázar, que reconheceram no gênero alguns elementos comuns para sua definição, por exemplo; técnica, concisão, tensão, intensidade, unidade de efeito e rigor estilístico. Escolher escritores, em vez de teóricos ou críticos estritos, justifica-se não somente pelo fato de suas reflexões serem relevantes para os estudos sobre o tema, mas também pelo interesse em nos aprofundarmos na estrutura do conto pelo viés da práxis.

Palavras-chave: Conto; Teoria do conto; Conto breve.

\begin{abstract}
This article examines the short story as an autonomous literary genre. To this end, we revisit some of the theoretical essays of notable $19^{\text {th }}$ and $20^{\text {th }}$ century shortstory writers, namely: Edgar Alan Poe, Anton Chekhov, Horacio Quiroga, and Julio Cortázar, each of whom identified common defining elements in the genre, including: technique, concision, tension, intensity, unique effect, and stylistic rigor. The decision to select writers rather than theoreticians or critics, per se, was based not only on the relevance of their considerations for the study of the subject matter, but also on the broader interest of extending the analysis into the structure of short stories from their praxis.
\end{abstract}

Keywords: Story; Theory of the story; Short story.

\footnotetext{
1 Doutoranda em Literatura e Práticas Sociais pelo Programa de Pós-Graduação em Literatura da Universidade de Brasília ((PósLIT/UnB). Mestre em Literatura (UnB, 2009) e Graduada em Letras pela Universidade Federal de Uberlândia (UFU, 2003). Possui experiência na área de Letras, com ênfase em teoria literária, literatura brasileira e hispano-americana, língua espanhola e tradução. Como tradutora independente, em 2010 ganhou o Prêmio Novos Tradutores do Brasil. E-mail: rosita.ueno@gmail.com
} 


\section{O CONTO EM CONTEXTO}

O termo conto deriva do verbo "contar", do latim computare. Na Idade Média, as narrativas nesse estilo recebiam nomes como fábulas, apólogos, exemplos, provérbios, façanhas, novela. Os renascentistas costumavam usar o termo para se referirem a histórias simples, como o chiste, a anedota, os casos curiosos, frequentemente de origem oral, popular ou fantasiosa. No século XVIII, o termo foi resgatado pelos românticos para distinguir as narrações de viés fantástico, dado o seu caráter fantasioso. A partir da segunda metade do século XIX, o vocábulo passou a designar um gênero de prestigio literário reconhecido, tal como atualmente.

O conto remonta, portanto, à tradição oral que, antes mesmo do processo da escrita ou da urbanização, já ocupava um lugar privilegiado nas culturas primitivas, servindo muitas vezes como um recurso didático e/ou religioso, capaz de explicar as origens, o destino e o conjunto de crenças de um povo, bem como os fenômenos naturais e sociais de determinada cultura. Contudo, é notadamente da sua qualidade de entretenimento que esse modo discursivo cobra maior credibilidade, uma vez que o contato do homem com a narrativa - seja ela oral ou escrita - vem a ser um recurso que permite uma abertura no imaginário, um espaço através do qual é permitido ao homem refletir, compreender, sonhar, duvidar e experimentar novas realidades.

Uma revisão sobre a teoria permite notar que, tanto para os contistas como para a crítica, o início e o final do relato são de fundamental importância para o gênero. Digressões e ambientações desnecessárias devem ser eliminadas na composição de um bom relato. Tanto é assim que, na tradição oral, o uso da expressão "era uma vez", no início da narração, elimina qualquer descrição prévia de ambiente, indo diretamente à ação, seja ela física ou psicológica. Para o contista dominicano Juan Bosch, o "era uma vez" funcionou sempre como uma conjuração, algo capaz de instalar o ouvinte no meio da trama; trata-se de um principiar que já se encontra muito próximo do cerne do relato. Bosch acredita que essa técnica ainda é viável para se começar um conto, cujo "princípio não se deve encontrar a muita distância do próprio núcleo do conto, a fim de evitar que o leitor se canse". (BOSCH apud PACHECO et. al., 1993, p. 368, tradução nossa).

A dificuldade de definir e conceituar o gênero conto fez com que boa parte da crítica apelasse para metáforas e comparações, no intuito de traçar um conceito para 
aquilo que Cortázar denominou de "caracol da linguagem, irmão misterioso da poesia". (CORTÁZAR, 1974, p. 149).

Ao renunciar à função doutrinal, muito utilizada na Idade Média, o gênero conto deixa de ser um produto da cultura popular para ser uma manifestação literária. Essa liberdade estética talvez o tenha aproximado do romance a ponto de ser confundido com um subgênero deste, mas, não obstante, o conto continua "governado por um princípio estético estável, que provém de seu antecedente oral e que lhe permite jogar criativamente dentro de um padrão estético limitado". (SARDUNÍ D’ACRI, 2005, p. 92).

Mas em que consiste um conto? Que elementos o diferenciam do romance, uma vez que ambos pertencem ao gênero narrativo? A busca de uma resposta para essas perguntas faz com que recaiamos em sua extensão, que é certamente o eixo central sobre o qual convergem as reflexões daqueles que teorizaram sobre o gênero. Sabemos, porém, que a brevidade, por si só, não deve ser considerada como fator exclusivo capaz de determinar se um relato constitui ou não um conto, pois, ainda que esse critério tenha sido usado como elemento de diferenciação entre o romance e o conto, devemos ter claro que nem todo conto é breve, assim como nem todo romance é extenso.

$\mathrm{Na}$ tentativa de entender melhor os fatores que definem o gênero, Juan Bosch assinala que alcançar um bom relato é uma tarefa que requer técnica, uma técnica muito mais acurada do que aquela necessária à realização de um bom romance. Segundo o dominicano, na fatura do romance, o texto e os personagens podem rebelar-se, impondose à vontade do autor, o que motiva um final, muitas vezes, diferente daquele imaginado por seu criador. Esse processo seria impossível no conto, que deve ser "obra exclusiva do contista. Ele é o pai e o ditador de suas criaturas, não pode deixá-las livres nem tolerar suas rebeliões" (BOSCH, 1993, p. 367, tradução nossa). Convém que esse domínio do contista se manifeste antes mesmo do processo escritural, por meio de uma disciplina mental e emocional que vai desde a escolha do tema até sua organização e posterior manifestação no processo da escrita, que ocorrerá sempre e quando o conto já estiver elaborado por completo no nível mental. Essa tarefa requer tanta tensão quanto aquela desejada para o leitor, cujo interesse deve ser mantido vivo durante todo o ato da leitura.

Temos, assim, alguns elementos que serão comuns a vários teóricos do conto: técnica, concisão, tensão, intensidade, unidade de efeito, rigor estilístico. Veremos, a seguir, como se espera que esses elementos sejam trabalhados pelo contista, na visão de 
escritores que se dedicaram ao relato breve, e como os teóricos do conto analisam esses mesmos elementos como traços definidores do gênero.

Ao registrar suas reflexões sobre o processo criativo os escritores não costumam seguir a sistematização teórica dos críticos ou acadêmicos, mas expressam uma percepção aguçada e interior dos problemas que perfazem a gênese do objeto literário, fato que consideraremos no decorrer deste artigo.

\section{Edgar Allan Poe: a composição do gênero}

Os anos de 1840 refletem, em boa medida, um momento de popularização e consequente propagação do conto em várias revistas e jornais da Europa e da América do Norte. Em face do volume de narrativas curtas publicadas naquele período, o escritor americano Edgar Alan Poe sente a necessidade de abstrair algumas noções básicas e de estipular certos conceitos para um gênero que, em sua opinião, oferece melhor campo para o talento literário que o romance. Por conseguinte, em 1842, Poe escreve sua conhecida resenha crítica Contos contados duas vezes, de Nathaniel Hawthorne (POE, 2003, p. 65-72), a respeito de Twice-Told Tales, de seu contemporâneo Hawthorne, esses “contos contados duas vezes" foram publicados em periódicos da época e, posteriormente, reunidos em volumes únicos (1837 e 1842); sendo esta última edição, revisada por Poe, e inspirando-o a escrever uma resenha crítica na qual expõe seus pontos de vista sobre a teoria do conto.

Tanto na resenha mencionada quanto na Filosofia da composição (1846), que descreve o processo escritural do conhecido poema $O$ corvo, há uma questão que recebe especial atenção de Poe: a insistência na necessidade de concisão ou, ainda, da extensão justa para comover o ânimo do leitor. O contista estadunidense chega a estipular qual deve ser o tempo ideal de leitura de um conto ou de um poema: de meia hora a duas horas no máximo, em uma única sessão ou "assentada". Em suas reflexões, a concisão está intimamente ligada ao objetivo fundamental do conto: produzir uma unidade de efeito. $\mathrm{O}$ efeito organiza a escolha dos incidentes a serem narrados, o tom e o vocabulário: tudo deve estar subordinado a ele. Como Poe define o efeito? Como um sentimento de excitação intensa, seguindo a habitual linha romântica de pensamento com a qual ele se identificava. Em sua concepção, o propósito último da literatura é o de impressionar a alma do leitor e roubar-lhe a atenção: "Poe escreverá seus contos para dominar, para submeter o leitor no plano imaginativo e espiritual” (CORTÁZAR, 1974, p. 121). 
Embora pareça que a principal preocupação de Poe, como crítico do conto, se relacione diametralmente com a questão da extensão, sabemos que ele percebeu, "antes de todos, o rigor que exige o conto como gênero, e que as diferenças deste com relação ao romance não eram só uma questão de tamanho" (CORTÁZAR, 1974, p. 122). É evidente que, para Poe, a crítica ao romance como gênero literário deriva da incapacidade deste último de produzir a almejada unidade de efeito. A extensão dilatada do romance exige uma leitura interrompida, em que a cotidianidade distrai o leitor, tornando-se impossível a sensação de intensidade e totalidade. Para Poe, a obra literária de maior mérito deve evitar essa dilatação criticável do romance comum, assim como uma brevidade extrema, dado que, para que a sensação de unidade de efeito se realize, deve existir certa duração ou repetição proposital.

Em Poe, a intensidade é um recurso que conferirá não apenas um critério de economia ao conto, mas uma força de articulação exata entre as partes, o que nos faz pensar numa maquinaria verbal, em que o encadeamento de cada palavra contribui para formar uma engrenagem perfeita. Nesse sentido, a economia não é apenas uma questão de ajuste entre o tema e o relato em si, mas, sobretudo, a junção disso à sua expressão verbal, capaz de alcançar uma amplitude que ultrapassa os limites do conto (Cf.: CORTÁZAR, 1974, p. 124-125). Essa amplitude é o resultado do que entendemos por intensidade, ou seja, um recurso capaz de permitir que o texto ultrapasse a mera história que narra, apresentando ao leitor uma dimensão outra, na qual a pequena história ganha novos e diferentes significados, provocando no leitor aquela sensação que Cortázar definiu como um "tremor de água no cristal” (CORTÁZAR, 1974, p. 150-151).

Poe acredita que o melhor terreno para a expressão do talento literário é o poema lírico de uma extensão não maior que cem versos. No entanto, defende a ideia de que o propósito último do poema, além do ritmo, é a experiência da Beleza. Contudo, o objetivo do conto não é primordialmente a beleza, senão a Verdade, mais fácil de ser “alcançada por meio da prosa". Beleza e Verdade são termos são tratados por Poe em maiúsculo, pois, seu intuito é o de enfatizar sua inscrição na ontologia de tradição platônica e na doutrina kantiana. Embora ele reconheça a aproximação existente entre o conto e a poesia, esta é considerada pelo norte-americano como o mais elevado dos gêneros literários, não obstante ele admita que o conto permite uma extensão maior de tons e efeitos, de inflexões de pensamento e expressão. Nesse ponto, ele acredita que a 
verdade - verossimilhança - depende de um raciocínio exato e que este e os demais componentes do texto devem estar unidos em favor do prazer da leitura.

Em Poe temos, então, duas diretrizes do conto que o escritor deve combinar: a capacidade dedutiva que lhe permita construir o conto como um processo cerebral, como maquinaria verbal e, consequentemente, a habilidade de suscitar no leitor emoções como o horror ou a novidade. Por conseguinte, em suas reflexões teóricas encontram-se os primeiros e mais influentes preceitos acerca do processo escritural e da busca de um método para a gênese do conto. Praticamente nenhum contista de importância, até o final do século XX, deixou de considerá-las como fundamentais para sua práxis.

Considerando-se a brevidade e a unidade como recursos fundamentais para a concepção do conto moderno, além de certo rigor estilístico, há também dois autores que, apesar da distancia geográfica, compartilharam ideias comuns acerca da concepção do conto, e que cabem à nossa menção, a saber, o escritor russo Anton Tchekhov (18601904) e o uruguaio Horacio Quiroga (1878-1937).

\section{Tchekhov - o cotidiano é o mais surpreendente dos mundos.}

Embora tenha alcançado grande destaque como dramaturgo, Tchekhov pertence, sem dúvida, à categoria dos contistas no cenário da literatura universal. Ele soube trabalhar o conto de maneira a transgredir as concepções literárias baseadas na tradição, o que lhe rendeu a fama de renovador e até mesmo de grande criador do conto moderno, não obstante, as acusações sofridas em sua época ou em consequência destas: indiferença ao bem e ao mau, ausência de uma postura ideológica explícita e contos com finais inacabados ou desfecho banal.

De qualquer modo, o rigor formal, a concisão e a preocupação com o efeito que se quer gerar no leitor - ainda que por meios diferentes - revelam uma aproximação entre Poe e Tchekhov, e isto certamente nos leva a antever aquilo que Cortázar, quase um século depois, chamaria de "certas constantes, certos valores que se aplicam a todos os contos." (CORTÁZAR, 1974, p. 149).

Por outro lado, Tchekhov não visava o efeito em crescendo orientado a um desfecho surpreendente, como se a narrativa percorresse um trajeto ascendente. A tônica da narrativa devia residir no desenrolar dos incidentes e não necessariamente no seu final. Ao escritor russo importava que a trivialidade dos textos coincidisse com a realidade banal e cotidiana do homem comum; e isso é o que se percebe em $O$ bilhete premiado, 
narrativa que se desenvolve a partir da possibilidade de um bilhete de loteria contemplar o casal Macha e Ivan Dmítritch. Entusiasmados com a sequência de números coincidentes entre o bilhete que possuem e aqueles publicados no jornal, eles começam a imaginar todos os benefícios que o dinheiro traria, deixando a confirmação do último número em suspenso. À medida que dão vazão aos sonhos, as vantagens do enriquecimento evoluem, no imaginário do casal, para sentimentos negativos, como desconfiança, disputa de poder, avareza, desejo de desfrutar do dinheiro ao lado de outra pessoa. Na sequência, o marido consulta e anuncia o último número do bilhete premiado, que não coincide com o número final do bilhete que possuem. Em um instante, tudo volta ao ponto de partida, ou seja, toda a mediocridade cotidiana do casal se impõe novamente, de modo irremediável; mais do que isso, o bilhete abre um leque de frustrações e reprimendas sucessivas. Portanto, a narrativa que Tchekhov nos oferece é a da contiguidade entre a ficção e a realidade, ambas inesgotáveis.

Ainda que as reflexões de Tchekhov, no que se refere à estética do conto, não visassem uma publicação de teor crítico, como no caso de Poe, elas foram dadas a conhecer em 1924 por meio da publicação das cartas do contista enviadas a seus pares: amigos, escritores e editores. Nessas correspondências, Tchekhov emite opiniões sobre os contos de seus amigos e os aconselha no intuito de que seus textos tenham mais sabor para o público leitor. Os principais preceitos do contista russo dizem respeito à contenção, concisão, simplicidade, sobriedade, desalento existencial vivido pelos personagens e negação de uma subjetividade aparente naqueles, presença de episódios pequenos e cotidianos, pausas longas, ausência de desfecho e de fatos grandiloquentes.

\section{O receituário abreviado de Quiroga}

Os valores estéticos defendidos por Tchekhov foram posteriormente retomados pelo escritor uruguaio Horácio Quiroga, para quem a brevidade, a concisão e o ascetismo deveriam ser preocupação capital de qualquer contista. Quiroga não foi um pensador estrito das condições e possibilidades do gênero contístico como seu mestre Poe; no entanto, foi capaz de elaborar reflexões sobre aspectos teóricos do conto, baseadas, sobretudo, na sua prática intensa e em breves artigos publicados em revistas da época. Dessas reflexões destacam-se o Manual do perfeito contista, publicado originalmente em 
1925 e o Decálogo do perfeito contista, de 1927. De acordo com o próprio autor, o primeiro deles seria uma anotação de truques de tom mais humorístico do que solene.

A fim de comentar os preceitos expressos no Decálogo do perfeito contista e compará-los com os ideais composicionais de Tchekhov, por quem Quiroga assume explicitamente sua admiração já na primeira cláusula, vale a pena observar abaixo as dez regras básicas propostas pelo uruguaio nesse decálogo:

\footnotetext{
I - Crê em um mestre - Poe, Maupassant, Kipling, Tchekhov - como em Deus.

II - Crê que tua arte é um cume inacessível. Não sonhes alcançá-la. Quando puderes fazê-lo, conseguirás sem ao menos perceber.

III - Resiste o quanto puderes à imitação, mas imite se a demanda for demasiado forte. Mais que nenhuma outra coisa, o desenvolvimento da personalidade requer muita paciência.

IV - Tem fé cega não em tua capacidade para o triunfo, mas no ardor com que o desejas. Ama tua arte como à tua namorada, de todo o coração. (QUIROGA, [1927], 1999, s.p).
}

Ao assinalar os princípios de conduta que o autor "perfeito" deve ter para com a tradição literária, sua índole artística e a arte em geral; os quatro primeiros pontos revelam uma doutrina que exige do escritor uma rigorosa ortodoxia. Dessas primeiras máximas se depreende que o contista é sempre um aprendiz, fato que remete às antigas práticas artesanais da Idade Média, cujo longo exercício converte o discípulo em mestre. Paciência e humildade são as virtudes que o perfeito contista deve possuir, ou seja, paciência para fazer da prática um exercício contínuo a fim de alcançar a perfeição, e humildade para amar e seguir os mestres que precedem ao discípulo.

Os quatro pontos seguintes referem-se ao estilo e, à maneira de Tchekhov, também comportam um ideário ascético: as palavras, sem importar se são assonantes ou consonantes, devem ser justas e precisas, acompanhadas de poucos adjetivos, com recorte de tudo o que não seja essencial ao enredo:

V - Não comeces a escrever sem saber desde a primeira linha aonde queres chegar. Em um conto bem-feito, as três primeiras linhas têm quase a mesma importância das três últimas.

VI - Se quiseres expressar com exatidão esta circunstância: "Desde o rio soprava o vento frio", não há na língua humana mais palavras que as apontadas para expressá-la. Uma vez dono de tuas palavras, não te preocupes em observar se apresentam consonância ou dissonância entre si. (QUIROGA, [1927], 1999, s.p). 
O uso excessivo dos adjetivos parece ser uma preocupação comum a vários teóricos do conto, talvez porque esse emprego abusivo esbarre diretamente na questão da concisão, objetivo fundamental de todo contista. Tanto nas cartas de Tchekhov quanto no decálogo de Quiroga recomenda-se que a adjetivação desnecessária seja banida para que se consiga um conto bem realizado. Para Tchekhov, "em contos é melhor não dizer o suficiente que dizer demais" (ANGELIDES, 1995, p. 210). O uso de substantivos e adjetivos em excesso dificulta a concentração do leitor. Do mesmo modo, convém evitar a subjetividade das cenas e dos personagens. Ao leitor cabe o papel de desenvolver, por meio da imaginação, os elementos acessórios da cena, que requer uma descrição clara e objetiva por parte do contista, já que leitor possui, por si só, a capacidade de acrescentar "os elementos subjetivos de que carece o conto":

VII - Não adjetives sem necessidade. Inúteis serão quantos apêndices coloridos aderires a um substantivo fraco. Se encontrares o perfeito, somente ele terá uma cor incomparável. Mas é preciso encontrá-lo.

VIII - Pega teus personagens pela mão e conduza-os firmemente até o fim, sem ver nada além do caminho que traçastes para eles. Não te distraias vendo o que a eles não importa ver. Não abuses do leitor. Um conto é um romance do qual se retirou as aparas. Tenha isso como uma verdade absoluta, ainda que não o seja. (QUIROGA, [1927], 1999, s.p).

$\mathrm{O}$ ato de tomar o personagem pela mão e não se distrair com a própria subjetividade é uma ideia também expressa por Tchekhov quando diz que o autor deve "renunciar a si mesmo, ainda que seja por meia hora" (TCHEKHOV apud PACHECO et LINARES, 1993, p. 317, tradução nossa). Ele precisa "pensar e falar o tempo todo como eles [os personagens], sentir com seus sentimentos"; do contrário, se o contista permite que sua subjetividade se introduza, "a imagem se des-desenhará e o conto já não será tão compacto como deve ser" (TCHEKHOV apud PACHECO et LINARES, 1993, p. 320, tradução nossa).

A ideia que se repete de forma subjacente nas cartas de Tchekhov e, sobretudo, no decálogo de Quiroga é a da austeridade: negação do eu, entrega a uma causa e resistência aos excessos. Esse rigor é uma consequência da extrema tensão mental do contista, que não lhe permite nenhum preciosismo, divagação ou frouxidão. Essa tensão, segundo o uruguaio, é a base fundamental do conto. A negação do eu, citada acima, pode ser vista ainda, com maior clareza, nos dois últimos preceitos de Quiroga: 
IX - Não escrevas sob domínio da emoção. Deixe-a morrer e evoque-a em seguida. Se fores então capaz de revivê-la tal qual a sentiu, terás alcançado na arte a metade do caminho.

$X$ - Não penses em teus amigos ao escrever, nem na impressão que causará tua história. Escreva como se teu relato não interessasse a mais ninguém senão ao pequeno mundo de teus personagens, dos quais poderias ter sido um. Não há outro modo de dar vida ao conto. (QUIROGA, [1927], 1999, s.p).

O lugar da enunciação de Quiroga é o do mestre, cuja função é orientar o aprendiz de na arte de escrever contos. O uruguaio, quando fala da técnica do conto, pode ser até mesmo irônico, como se constata nos conselhos propostos no Manual do perfeito contista, texto que não oculta um fino sarcasmo quanto aos procedimentos sugeridos para lograrse um bom conto. Nesse ensaio, Quiroga afirma que apresentará algumas receitas seguras que podem facilitar a prática daquilo que se convencionou chamar de o mais difícil dos gêneros literários, a saber: "[...] Contentemo-nos, por hora, com a exposição de três ou quatro receitas das mais usuais e seguras, convencidos de que elas facilitarão a prática cômoda e caseira do que se convencionou chamar de o mais difícil dos gêneros literários" (QUIROGA, 1993, p. 328).

Ele faz uma revisão das fórmulas que podem ser usadas no início e final dos contos, segundo ele, valendo-se das "receitas ou truques de procedimento ao alcance de todos" (QUIROGA, 1993, p. 327), como é o caso do uso de frases de efeito, por exemplo. É mais conveniente, assinala Quiroga, que os finais dos relatos constem de orações breves e, no possível, exclamativas; os princípios devem ser curtos e diretos; é desejável que o contista proceda como se o leitor já conhecesse o início da história que lhe será narrada; explicações sobre o perfil dos personagens ou sobre acontecimentos anteriores são desnecessárias. Quiroga tem consciência de que essas receitas, ainda que coincidam com alguns procedimentos usados em contos de reconhecido valor literário, não são nenhuma garantia de êxito quando dissociadas do oficio de escritor mencionado por Poe e Cortázar; daí o cinismo do contista uruguaio. Nesse sentido, cabem as palavras de Mario de Andrade quando afirma que os grandes contistas não têm esse ou aquele grande conto, senão que descobriram a forma do conto, que é "indefinível, insondável, irredutível a receitas" (ANDRADE, [s.d.]. p. 7).

Contrariando Tchekhov, Quiroga chega inclusive a defender o lugar comum, ou seja, um tipo de recurso que deve ser explorado pela "má fé” do contista. Ele afirma que esse lugar comum pode ser cultivado pelo uso de expressões corriqueiras 
inseridas em um contexto incomum: "a má fé se constitui na falta de correlação entre a frase feita e o sentimento ou circunstância que a inspiram" (QUIROGA, 1993, p. 331, tradução nossa). Como exemplo, cita a expressão "ficar pálido", expressão que, em consequência da visão de um cadáver, é perfeitamente natural e não provoca nenhum sobressalto, mas, se usada diante de uma pessoa viva, adquire um relevo incomum, transformando-se em uma característica insólita que só será entendida depois que o leitor já se tenha entregado, de boa fé, ao desenrolar da história narrada (idem). Nesse sentido, a frase inicial do conto Parábola del trueque (1952), do mexicano Juan José Arreola, traz em seu bojo um exemplo dessa má fé defendida por Quiroga: "ao grito de 'troco esposas velhas por novas' o mercador percorreu as ruas do vilarejo arrastando seu comboio de pintados carroções" (ARREOLA, 1986, p. 153, tradução nossa). A frase apregoada pelo mercador é bastante usual para a venda de mercadorias, mas totalmente desconcertante em se tratando da venda, ou troca, de esposas.

A máxima principal dos preceitos de Quiroga é que o conto deve prender, desde o início, a atenção do leitor e não soltá-la até o final; isso revela que o escritor uruguaio se inscreve, de maneira ortodoxa, à escola de Poe e de Tchekhov, que pregavam que não se pode permitir ao leitor a oportunidade de recuperação - desvio do texto -, e que ele deve ser mantido em suspenso durante todo o ato da leitura.

Posteriormente, em La retórica del cuento (1928), dessa vez com um tom mais solene que humorístico, Quiroga afirma que o conto, contrariamente a outros gêneros, não sofreu variações no decurso do tempo; e postula, inclusive, que se algum dia o conto vier a sofrer alterações em sua constituição, ou seja, em seu cânone, que este seja chamado de outra coisa e não mais de conto.

\section{Julio Cortázar - metáforas para a definição de conto}

Julio Cortázar foi grande influente entre os contistas argentinos da segunda metade do século XX e, embora tenha alcançado êxito de público como integrante do chamado boom dos anos sessenta, com romances como Rayuela (1963), há um consenso entre críticos e escritores ao afirmarem que o mais relevante de sua produção pertence à categoria conto.

Quanto a esse gênero, Cortázar é um renovador cauteloso, sempre atento ao que ele mesmo chamou de constantes da prosa breve, bem como às modificações que, sem 
romper radicalmente com o modelo estabelecido pela tradição, vivificam o gênero. Daí a importância de suas reflexões apresentadas num texto-conferência ditado em Cuba, o Alguns aspectos do conto (1970/1974).

Cortázar inicia a sua conferência ressalvando que suas reflexões acerca do conto partem de um ponto de vista pessoal, e declara preferir o termo "fantástico", ainda que o considere vago, para qualificar grande parte de seus contos. Ao mesmo tempo, rebate o que chama de realismo ingênuo, que se fundamentaria no ideário do racionalismo do século XVIII. Apoiando-se no pensamento de Alfred Jarry, um dos inspiradores do surrealismo e do teatro do absurdo, Cortázar acredita que as exceções oferecem um campo maior para a expressão da realidade do que as leis propriamente ditas. Mais adiante, afirma que essa preferência pelo excepcional não o desabilita de apresentar o que considera elementos imutáveis que conferem ao bom conto um frescor peculiar e a qualidade de obra de arte.

O escritor argentino, assim como outros críticos e contistas, inicia sua exposição recorrendo ao já conhecido binômio romance e conto. Para Cortázar, Para Cortázar, antes de tudo, o conto define-se pela noção de limite. Se, por um lado, o romance não tem mais limite do que aquele imposto pela matéria romanceada, o conto opera de forma estrita com essa noção, inclusive com a noção de limite físico.

Quando Mário de Andrade afirmou que "será conto tudo aquilo que seu autor batizou com o nome de conto" (ANDRADE, [s.d.], p. 7), ele pensava mais na dificuldade de definição do gênero e menos na autoridade do autor para introduzir seu tex to na poética do conto. Essa dificuldade de definição é, certamente, a razão pela qual Julio Cortázar apela para a construção de imagens-metáforas e analogias para expor suas ideias a respeito da configuração do gênero.

Em Alguns aspectos do conto encontramos a ideia de que o romance está para o cinema assim como o conto está para a fotografia. O filme se desenvolveria em um espaço dilatado, não sem incluir um momento sintético que constitua o clímax da obra. A fotografia, por outro lado, dadas as limitações das lentes, deve escolher uma imagem precisa e limitar-se a ela. Mas essa imagem, segundo Cortázar, deve produzir uma abertura de sentido que faça com que a foto não caia na futilidade. Por conseguinte, ele afirma que o contista procede de maneira inversa à do romancista ou do diretor cinematográfico: parte de uma situação muito reduzida, mas cuidadosamente selecionada, de maneira a permitir uma abertura capaz de fazer com que o recorte - da foto ou do conto 
- "atue como uma explosão que abra de par em par uma realidade muito mais ampla" (CORTÁZAR, 1974, p. 151). Para Cortázar, uma vez que o contista não tem o tempo e o espaço a seu favor, em lugar de proceder cumulativamente, ele deve trabalhar verticalmente e em profundidade. Essas noções servem para que o contista argentino introduza os três valores fundamentais do que seria, a seu ver, um conto bem realizado: significação, intensidade e tensão (1974, p. 152).

Um conto é significativo quando rompe os limites do enredo, quando se converte na expressão de algum viés da condição humana. A significação se relaciona diretamente com o tema, com a escolha de determinados incidentes que não se esgotam no anedótico. Por mais corriqueiros que sejam, quando recebem um tratamento adequado, esses incidentes são capazes de propagar uma significação profunda, um conjunto de representações capaz de se converter no "resumo implacável de certa condição humana" (CORTÁZAR, 1974, p. 153).

Para o contista argentino não existem temas menos ou mais significativos. O que diferencia um bom conto de um mau conto é o procedimento literário dado ao tema. Quanto mais insignificantes forem os elementos circunstanciais do conto, mais poder ele tem de adquirir uma dimensão representativa, sempre e quando seja bem elaborado. Aliás, a escolha dos autores apontados por Cortázar em Alguns aspectos do conto, que são Katherine Mansfield e Anton Tchekhov, parece sugerir uma predileção por essa temática ínfima, corriqueira e cotidiana; oposta à acumulação de fatos extraordinários e à comoção declarada.

Cortázar chega à conclusão de que conto e poesia têm uma gênese comum, pois ambos nascem de "um repentino estranhamento, de um deslocamento que altera o regime 'normal' da consciência". E acrescenta: "minha experiência me diz que, de algum modo, um conto breve como os que procurei caracterizar não tem uma estrutura de prosa" (CORTÁZAR, 1974, p. 234). Por conseguinte, embora faça um esforço teórico importante para se manter dentro dos limites do estritamente literário, a proximidade do conto com o trabalho poético faz que o argentino aluda a uma espécie de mistério, de aura, de transe ou bicho que aflige o escritor, mas que faz dele, surpreendentemente, um verdadeiro artista:

[...] um contista eficaz pode escrever narrativas literariamente válidas, mas se alguma vez tiver passado pela experiência de se livrar de um 
conto como quem tira de cima de si um bicho, saberá a diferença que há entre possessão e cozinha literária. (1974, p. 231).

Assim, quando se depara com a dificuldade de explicar determinados processos literários da gênese contística, Cortázar parece apelar para uma espécie de telepatia entre autor e leitor; ou considera-se um médium, posto que não consegue explicar por que alguns temas lhe são impostos por uma força alheia à sua vontade. Essa junção de observações técnicas pontuais muito agudas e de apelações a um sentir pragmático explicaria as origens e o efeito da obra literária, sendo também uma característica da formação intelectual de Cortázar, presente também no surrealismo, uma das vanguardas do século XX que mais o influenciou.

Em síntese, pode-se dizer que, na visão de Cortázar, o conto vai do pequeno ao grande, do corriqueiro ao extraordinário, do insignificante ao significativo. A excelência de um conto virá sempre de um tema excepcional, o que não significa que o mote deva ser extraordinário, simbólico ou insólito, mas capaz de estabelecer uma conexão entre o contista e o leitor, uma comunicação similar àquela dada pelo poema ou pelo jazz: a tensão, o ritmo, a pulsação interna, "o imprevisto dentro de parâmetros pré-vistos, essa liberdade fatal que não admite alteração sem uma perda irreparável” (CORTÁZAR, 1974, p. 235). Para o autor argentino, os contos dessa natureza "incorporam-se como cicatrizes indeléveis em todo leitor que os mereça: são criaturas vivas, organismos completos, ciclos fechados, e respiram" (1974, p. 235). Nisso reside, segundo Cortázar, a qualidade memorável das melhores obras do gênero.

\section{CONSIDERAÇÕES FINAIS}

Apesar das dificuldades de apreensão do gênero, os postulados discutidos acima, constatamos que a concisão, elemento central do conto contemporâneo, se contrapõe, sobretudo, ao romance como o modelo de gênero narrativo mais tratado pela crítica, ao comprimir em um pequeno espaço significações que o romance desdobraria em um continuиm que pretende imitar a vida.

A intensidade, elemento também comum para os autores estudados, permite que se saia de um grande conto breve, "como de um ato de amor, esgotado e fora do mundo circundante, ao qual se volta pouco a pouco com um olhar de surpresa". (CORTÁZAR, 1974, p. 231). 
Embora seja anterior à escrita e tão antigo quanto a linguagem, como gênero literário o conto veio ganhando reconhecimento e autonomia tão somente a partir do século XX. O surgimento de uma gama cada vez maior de antologias de contos tem mostrado que o ex-parente pobre do romance ganhou bastante terreno entre as publicações literárias das últimas décadas. As reflexões de Poe, Tchekhov, Quiroga e Cortázar tornaram-se relevantes para os estudos sobre o tema, tendo suprido, em boa medida, a carência de fortuna crítica que havia até então.

\section{REFERÊNCIAS}

ANGELIDES, S. A. P. Tchékhov: cartas para uma poética. São Paulo: Edusp, 1995.

ARREOLA. J. J. Confabulario definitivo. Edición de Carmen de Mora. Madrid: Ediciones Cátedra S. A., 1986.

BOSCH, J. Apuntes sobre el arte de escribir cuentos. In: PACHECO, C.; BARRERA LINARES, L. (Compiladores). Del cuento y sus alrededores: aproximaciones a una teoría del cuento. Caracas: Monte Ávila Editores Latinoamericana, 1993.

CORTÁZAR, J. Valise de Cronópio. Tradução de Davi Arrigucci Jr. e João Alexandre Barbosa. São Paulo: Perspectiva, 1974.

DRUCAROFF, E. Fantástico desencantado: los nietos de Julio Cortázar. Axxón: Revista argentina en español en soporte informático de Ciencia Ficción, Fantasía y Terror, n.155 - octubre de 2005. Disponível em: 〈http://axxon.com.ar/rev/155/c-155ensayo.htm> Acesso em: 07 jan. 2009.

PACHECO, C.; BARRERA LINARES, L. (Compiladores). Del cuento y sus alrededores: aproximaciones a una teoría del cuento. Caracas: Monte Ávila Editores Latinoamericana, 1993.

PINTO, A. D. Princípios poéticos e tradição nos contos de Edgar Allan Poe e de Álvaro do Carvalhal. Universidade do Algarve e Centro de Estudos Comparatistas (FLL). Disponível em:

<www.eventos.uevora.pt/comparada/VolumeII/PRINCIPIOS\%20 POETICOS\%20E\%20TRADICAO.pdf> Acesso em: 15 jun. 2008.

POE, E. A. A filosofia da Composição. In: A filosofia da Composição. Poemas e ensaios. Tradução de Oscar Mendes e Milton Amado. Rio de Janeiro: Globo, 1985. 101112p. (Biblioteca dos Séculos).

Contos contados duas vezes, de Nathaniel Hawthorne. In: Revista Cerrados. Publicação do Departamento de Teoria Literária e Literatura do Programa de PósGraduação em Literatura da UnB, ano 12, n.16, (2003). Brasília, 2003. 133p. 
Histórias extraordinárias. São Paulo: Companhia das Letras. 2008. 272p. QUIROGA, Horacio. Decálogo del perfecto cuentista. Disponível em: <www.ciudadseva.com> Acesso em: 13 fev. 2007.

Decálogo do perfeito contista. São Leopoldo: UNISINOS, 1999.

El manual del perfecto cuentista. In: PACHECO, Carlos e BARRERA LINARES, Luis (compiladores). Del cuento y sus alrededores: aproximaciones a una teoría del cuento. Caracas: Monte Ávila Editores Latinoamericana, 1993.

Todos los cuentos. Edición crítica. N. B. Poince de León y J. La forgue (org.). ALLCA - XX - UFRJ Editora. Col. Archivos. n.26. [s.d.].

SARDUNÍ D'ACRI, T. R. Arreola y Monterroso: tradición y modernidad en el cuento mexicano. In: Revista de crítica literaria latinoamericana. Año XXXI, n. 61, LimaHanover, primer semestre de 2005, p. 91-109.

SILVA Y ACEVES, M. Mariano Silva y Aceves: material de lectura. Selección y nota de Beatriz Espejo. México: Universidad Nacional Autónoma de México, 2008, p. 24. (Serie El Cuento Contemporáneo, núm. 40).

TCHEKHOV, A. P. Cartas para uma poética. Org. Sofia Angelides. São Paulo: Edusp, 1995. 323.

Cartas sobre el cuento. In: PACHECO e BARRERA LINARES, 1993, p. 315-

TODOROV, T. As estruturas narrativas. São Paulo: Editora Perspectiva, 1979. 